\title{
Phenotypic and genetic parameters for growth traits in Red Chittagong Cattle of Bangladesh
}

\author{
T. Rabeya, A. K. F. H. Bhuiyan, M. A. Habib and M. S. Hossain \\ Department of Animal Breeding \& Genetics, Bangladesh Agricultural University, Mymensingh 2202, Bangladesh
}

\begin{abstract}
The present study was carried out to estimate phenotypic and genetic parameters of Red Chittagong Cattle (RCC) for growth traits. Means of birth weight (BW), three month weight (3MW), six month weight $(6 \mathrm{MW})$, weaning weight $(\mathrm{WW})$, nine month weight $(9 \mathrm{MW})$ and yearling weight $(\mathrm{YW})$ were 15.74, 31.48, 45.33, 57.00, 60.91 and $76.18 \mathrm{~kg}$ respectively. Sex significantly $(p<0.001)$ differed BW of calves but did not differ $(p>0.05) 3 M W, 6 M W, W W, 9 M W$ and YW. BW, 6MW, WW, 9MW and YW did not vary significantly $(p>0.05)$ on year of birth but varied significantly $(p<0.01)$ on 3MW. Season of birth had significant difference on 3MW $(p<0.001), 6 M W(p<0.01)$ and WW ( $<<0.01)$ but had no significant difference $(p>0.05)$ on $B W, 9 M W$ and $Y W$. The growth rates at zero to six month (6MGR) and six to twelve month (12MGR) were 0.17 and $0.17 \mathrm{~kg} / \mathrm{d}$ respectively. Growth rate in both stages had no significant effect ( $p>0.05$ ) on sex and year of birth. 6MGR had no significant effect $(p>0.05)$ on season of birth but had significant $(p<0.05)$ effect on 12MGR. From single trait analyses heritability $\left(h^{2}\right)$ of BW, 3MW, 6MW, WW, 9MW, YW, 6MGR and 12MGR were $0.497,0.468,0.475,0.467,0.447,0.478,0.499$ and 0.65 , respectively, whereas from multi-trait analysis heritability $\left(h^{2}\right)$ of first four traits were $0.498,0.456,0.500$ and 0.490 , respectively. Genetic correlations of BW with $3 \mathrm{MW}, 6 \mathrm{MW}$ and $\mathrm{WW}$ were $0.23,0.38$, and 0.53 , respectively, $3 \mathrm{MW}$ with $6 \mathrm{MW}$ and WW were 0.78 and 0.69 , respectively and $6 \mathrm{MW}$ with WW was 0.76 . Estimated heritability values were rather high in magnitude and indicate that these traits would likely respond to selection. Estimates of phenotypic correlations among the traits studied were very low to moderate with values ranging from -0.40 to 0.81 , whereas magnitude of genetic correlation ranged from 0.23 to 0.78 . It was concluded that these estimated parameters would help to understand the biology of the traits and in designing breeding programme for other indigenous cattle in general.
\end{abstract}

Keywords: Phenotypic and Genetic parameters, Growth traits, Red Chittagong cattle

\section{Introduction}

Red Chittagong Cattle (RCC) which is not yet recognized as a breed is considered to be a valuable indigenous bovine genetic resource of Bangladesh with many attributes better than other available indigenous types and is readily distinguishable from others due to its distinct phenotypic features (Bhuiyan et al., 2007). It is a tropically adapted Bos indicus type cattle and best suited to typical low input range conditions. The main features of RCC lie on its ability to withstand extreme tropical climates and to survive on low quality feed during periods of feed shortage. On the other hand, growth and physiological aspects of the Bos indicus are unique genetic attributes, which are different from those of the Bos taurus breeds (Turner, 1980). Cartwright (1980) also stressed that the large differences exist in the anatomy and physiology of these animals compared to Bos taurus types, and therefore there might have some bearing on production. Due to indiscriminate crossbreeding along with improper feeding, poor husbandry and health management practices it has been pushed on the verge of extinction, (Bhuiyan et al, 2005). Therefore, data both on phenotypic and genetic parameters on RCC are to be made available for providing future guidelines in order to improve meat production potentiality of RCC in Bangladesh.

Faster growth rate is a very important trait while meat production is the target. Growth performances are important traits influencing profitability in the majority of beef production systems (Rege and Famula, 1993). Improvement of live performance traits is an increasingly important breeding goal in beef cattle and other livestock production systems (Peters et al., 1998). Therefore, knowledge on the genetic parameters of traits in the selection programme is needed to optimize breeding programme and to predict genetic response to selection. Meyer (1992) and Ferreira et al. (1999) indicated that an animal model that includes individual performance and pedigree information would provide the beef industry with reliable estimates of genetic parameters and should result in improved genetic evaluation programme. The manner in which this genetic improvement is to be achieved can be described using a selection objective (Van der Westhuizen and Matjuda, 1999). Then growth rate, the Breeding Value (BV) or genetic merit of each animal is to be estimated first in the population concerned. Heritability $\left(h^{2}\right)$ and genetic correlation $\left(r_{G}\right)$ estimation is the pre-requisite to estimate the genetic merit of individual animal constituting population and they are essential population parameters required in the design and application of practical animal breeding programme. 
In Bangladesh, numbers of studies have so far been carried out on phenotypic parameters of growth and body weights but study on genetic parameters particularly on indigenous cattle is scanty. That's why for designing indigenous cattle improvement programme in Bangladesh, the data on genetic parameter estimates such as heritability, repeatability and genetic correlation of growth trait(s) are very important to realize. Hence, the objectives of the study were: (a) to study phenotypic parameters on live weights and growth rates of Red Chittagong Cattle (RCC) (b) to estimate variance and covariance components followed by heritability $\left(h^{2}\right)$ and genetic correlation $\left(r_{G}\right)$ among the said traits.

\section{Materials and Methods}

\section{Source of data}

The data used in this study were collected from the Nucleus Herd of a USDA funded Red Chittagong Cattle project during the period from September, 2005 to September, 2008 carried out at the Department of Animal Breeding \& Genetics, Bangladesh Agricultural University, Mymensingh. Body weight data on individual animal was recorded at a regular basis of three months interval.

\section{Traits evaluated}

Traits included for this study were Birth weight (BW), Three month weight (3MW), Six month weight $(6 \mathrm{MW})$, Eight month adjusted weaning weight (WW), Nine month weight (9MW), Yearling weight (YT), Zero to six month growth rate (6MGR) and Six to twelve month growth rate (12MGR).

\section{Data structure}

The data structure according to traits studied with various classes and subclasses are given in Table 4 .

\section{Feeding and management of animals}

Stall feeding was followed throughout the years. Calves were supplied three different types of feeds such as green grasses (like maize, jumboo, napier, para, german etc.), concentrate mixture and rice straw (for suckling calves)/urea-molasses treated straw (for weaned calves). All feeds were supplied twice daily in the morning and evening. The feed allowance and composition are given in the Tables 1, 2 and 3 . Regular vaccination, deworming and medication were also performed.

Table 1. Feed allowance for RCC calves

\begin{tabular}{|l|c|c|}
\hline \multirow{2}{*}{ Types of feed } & \multicolumn{2}{|c|}{ Amount supplied (kg/day/individual) } \\
\cline { 2 - 3 } & Suckling calves & Weaned calves \\
\hline Green grasses & Ad libitum & Ad libitum \\
\hline Rice straw & Ad libitum & - \\
\hline Urea-molasses-straw & - & Ad libitum \\
\hline Concentrate mixture & 0.25 & 0.25 \\
\hline Water & Ad libitum & Ad libitum \\
\hline
\end{tabular}

Table 2. Composition of concentrate mixture

\begin{tabular}{|l|c|}
\hline Feed ingredients & Fresh amount (kg) \\
\hline Mustard oil cake & 20 \\
\hline Soybean meal & 20 \\
\hline Cracked maize & 50 \\
\hline Di-calcium phosphate (DCP) & 05 \\
\hline Common salt & 05 \\
\hline Estimated CP (g/kg DM) & 195 \\
\hline Estimated energy (MJ ME/kg DM) & 11.5 \\
\hline
\end{tabular}

Table 3. Composition of Urea-molasses-straw

\begin{tabular}{|l|c|c|}
\hline Components & DM basis (\%) & Fresh basis (\%) \\
\hline Rice straw & 82 & 91 \\
\hline Molasses & 15 & 21 \\
\hline Urea & 03 & 03 \\
\hline Water & & Equal to rice straw \\
\hline
\end{tabular}


Table 4. Distribution of data

\begin{tabular}{|l|c|c|c|c|c|c|c|c|}
\hline \multirow{2}{*}{ Trait } & \multicolumn{9}{|c|}{ Number of animals } \\
\cline { 2 - 11 } & \multicolumn{2}{|c|}{ Sex } & \multicolumn{3}{c|}{ Year } & \multicolumn{3}{c|}{ Season } \\
\cline { 2 - 11 } & Male & Female & 2006 & 2007 & 2008 & Summer & Rainy & Winter \\
\hline BWT & 48 & 41 & 33 & 25 & 17 & 25 & 22 & 34 \\
\hline 3MWT & 47 & 38 & 41 & 28 & 16 & 45 & 25 & 16 \\
\hline 6MWT & 44 & 35 & 32 & 21 & 26 & 45 & 14 & 20 \\
\hline WWT & 24 & 23 & 16 & 31 & - & 8 & 20 & 19 \\
\hline 9MWT & 28 & 24 & 7 & 22 & 23 & 31 & 16 & 5 \\
\hline 12MWT & 18 & 19 & 4 & 17 & 16 & 19 & 8 & 10 \\
\hline 6MGR & 44 & 35 & 32 & 21 & 24 & 45 & 14 & 20 \\
\hline 12MGR & 18 & 19 & 4 & 17 & 16 & 19 & 7 & 10 \\
\hline
\end{tabular}

\section{Data analyses}

The whole year was divided into three seasons to take an unbiased account of environmental variation. The three prominent seasons considered in the present experiment are summer (March-June), Rainy (July-October) and winter (November-February).

Means and standard errors (SE) for the traits studied were estimated using SPSS 11.50 computer package program. Variance and covariance components of the traits were estimated using Restricted Maximum Likelihood (REML) approach by VCE 4.2.5 computer program (Groeneveld, 1998) by fitting univariate and bivariate animal models. The total variance and covariance components were sorted into additive and non-additive (environmental and residual genetic) components. For REML analysis animal model was used keeping sex, year of birth and season of birth as fixed effect.

The following general mixed model was used for the analysis of data:

$$
\mathrm{Y}=\mathrm{Xb}+\mathrm{Za}+\mathrm{Wc}+\mathrm{e}
$$

Where, $Y=$ Vector of observation

$\mathrm{X}, \mathrm{Z}$ and $\mathrm{W}=$ Known incidence matrices that were associated with levels of $\mathrm{b}, \mathrm{a}, \mathrm{c}$ with $\mathrm{Y}$.

$b=$ Unknown vector of fixed effects (i.e. sex of calf, year of birth and season of birth)

$\mathrm{a}=$ Unknown vector of breeding value.

$\mathrm{c}=$ Unknown vector of permanent environmental effect.

$\mathrm{e}=$ Vector of residual effects.

Both single and multi-trait animal models were employed. The model used for BWT, 3MWT, 6MWT, WWT, 9MWT, 12MWT, 6MGR and 12MGR included the fixed effects of either season of birth or sex of animals. Direct additive genetic effects, permanent environmental effects and the residuals were fitted as random. Heritability and genetic correlation of the traits were estimated following procedures given by Falconer and MacKay (1996).

\section{Results and Discussion}

\section{Body weight and growth traits}

Means along with their standard errors (SE) for birth weight (BWT), three month weight (3MWT), six month weight (6MWT), weaning weight (WWT), nine month weight (9MWT), yearling weight (12 MWT), zero to six month growth rate (6 MGR), and six to twelve month growth rate (12MGR) are presented in Table 5.

Effect of sex of calves: Table 5 shows that male had higher $(p<0.001)$ BW $(15.74 \pm 0.32 \mathrm{~kg})$ than female $(13.89 \pm 0.34 \mathrm{~kg})$. This result agrees with the result of Alam et al. (2007) who reported $15.67 \mathrm{~kg} \mathrm{BW}$ for RCC males and $13.67 \mathrm{~kg}$ for RCC females. Habib et al. (2003) reported slightly higher BW of RCC calves as $17.24 \mathrm{~kg}$ for male and $16.00 \mathrm{~kg}$ for female. Anantakrishnan and Lazarus (1953) and Singh and Tyagi (1970) also reported that the sex of calves had significant influence on the BW. 
Table 5. Mean $( \pm$ SE) of the body weight and growth traits of Red Chittagong Cattle

\begin{tabular}{|c|c|c|c|c|c|c|c|c|}
\hline Trait & \multicolumn{2}{|c|}{ Sex } & \multicolumn{3}{|c|}{ Year of birth } & \multicolumn{3}{|c|}{ Season of birth } \\
\hline & Male & Female & 2006 & 2007 & 2008 & Summer & Rainy & Winter \\
\hline \multirow{3}{*}{ BWT (kg) } & $15.74^{\mathrm{a}}$ & $13.89^{b}$ & 15.06 & 15.25 & 14.94 & 15.02 & 13.67 & 15.35 \\
\hline & \pm 0.32 & \pm 0.34 & \pm 0.40 & \pm 0.47 & \pm 0.64 & \pm 0.55 & \pm 0.43 & \pm 0.36 \\
\hline & \multicolumn{2}{|c|}{ *** } & \multicolumn{3}{|c|}{ NS } & \multicolumn{3}{|c|}{ NS } \\
\hline \multirow{3}{*}{ 3MWT (kg) } & 31.48 & 29.58 & $28.34^{C}$ & $33.37^{a} \pm 1$ & $30.52^{b}$ & $51.50^{a}$ & $28.90^{\mathrm{C}} \pm 1$ & $32.61^{b}$ \\
\hline & \pm 1.06 & \pm 1.35 & \pm 1.12 & .49 & \pm 2.14 & \pm 22.41 & .68 & \pm 2.43 \\
\hline & \multicolumn{2}{|c|}{ NS } & \multicolumn{3}{|c|}{ ** } & \multicolumn{3}{|c|}{$\star * \star *$} \\
\hline \multirow{3}{*}{ 6MWT $(\mathrm{kg})$} & 45.33 & 46.10 & 44.98 & 46.02 & 45.17 & $45.33^{b}$ & $42.66^{C}$ & $48.39^{a}$ \\
\hline & \pm 1.49 & \pm 1.73 & \pm 1.50 & \pm 2.45 & \pm 2.20 & \pm 1.62 & \pm 2.48 & \pm 1.92 \\
\hline & \multicolumn{2}{|c|}{ NS } & \multicolumn{3}{|c|}{ NS } & \multicolumn{3}{|c|}{ ** } \\
\hline \multirow{3}{*}{ WWT (kg) } & 57 & 51.66 & 40.27 & 61.45 & & $54.93^{b}$ & $49.84^{C}$ & $56.83^{a}$ \\
\hline & \pm 3.23 & \pm 4.11 & \pm 3.28 & \pm 2.77 & - & \pm 6.91 & \pm 4.38 & \pm 3.48 \\
\hline & \multicolumn{2}{|c|}{ NS } & \multicolumn{3}{|c|}{ NS } & \multicolumn{3}{|c|}{ ** } \\
\hline \multirow{3}{*}{ 9MWT (kg) } & 60.91 & 60.31 & 59.00 & 63.18 & 57.31 & 62.48 & 57.08 & 61.15 \\
\hline & \pm 2.77 & \pm 3.1 & \pm 5.52 & \pm 2.00 & \pm 3.82 & \pm 2.82 & \pm 3.02 & \pm 6.59 \\
\hline & \multicolumn{2}{|c|}{ NS } & \multicolumn{3}{|c|}{ NS } & \multicolumn{3}{|c|}{ NS } \\
\hline \multirow{3}{*}{ 12MWT (kg) } & 76.18 & 73.70 & 73.04 & 77.08 & 77.34 & 76.66 & 74.00 & 77.84 \\
\hline & \pm 4.02 & \pm 3.27 & \pm 8.50 & \pm 2.49 & \pm 4.70 & \pm 3.72 & \pm 6.25 & \pm 4.23 \\
\hline & \multicolumn{2}{|c|}{ NS } & \multicolumn{3}{|c|}{ NS } & \multicolumn{3}{|c|}{ NS } \\
\hline \multirow{3}{*}{ 6MGR (g/day) } & 0.17 & 0.18 & 0.17 & 0.18 & 0.18 & 0.17 & 0.16 & 0.18 \\
\hline & \pm 0.007 & \pm 0.009 & \pm 0.008 & \pm 0.01 & \pm 0.01 & \pm 0.009 & \pm 0.01 & \pm 0.009 \\
\hline & \multicolumn{2}{|c|}{ NS } & \multicolumn{3}{|c|}{ NS } & \multicolumn{3}{|c|}{ NS } \\
\hline \multirow{3}{*}{ 12MGR (g/day) } & 0.17 & 0.17 & 0.19 & 0.15 & 0.15 & $0.16^{b}$ & $0.12^{c}$ & $0.19^{\mathrm{a}}$ \\
\hline & \pm 0.01 & \pm 0.01 & \pm 0.02 & \pm 0.01 & \pm 0.02 & \pm 0.01 & \pm 0.01 & \pm 0.01 \\
\hline & & & & NS & & & * & \\
\hline
\end{tabular}

${ }^{* * *}$ Means with uncommon superscripts along the row for sex or year of birth or season of birth differ significantly $(p<0.001)$

** Means with uncommon superscripts along the row for sex or year of birth or season of birth differ significantly $(p<0.01)$

Although male calves weighed heavier at 3MW (31.48 kg), WW (57 kg), 9MW (60.91 kg) and YW (76.18 $\mathrm{kg}$ ) than females $(29.58 \mathrm{~kg}, 51.66 \mathrm{~kg}, 60.31 \mathrm{~kg}$, and $73.70 \mathrm{~kg}$ respectively) but the differences between male and female calves were insignificant $(p>0.05)$. Female calves however at $6 \mathrm{MW}(46.10 \mathrm{~kg})$ slightly higher $(p>0.05)$ than male $(45.33 \mathrm{~kg})$. The 6MGR and 12MGR in male $(0.17 \mathrm{~kg} / \mathrm{d}$ and $0.17 \mathrm{~kg} / \mathrm{d})$ and female $(0.17 \mathrm{~kg} / \mathrm{d}$ and $0.18 \mathrm{~kg} / \mathrm{d})$ were more or less similar $(p>0.05)$.

Effect of year of birth: BW was not found to be affected by year. Effect of year of birth behaved similarly at $6 \mathrm{MW}, \mathrm{WW}, 9 \mathrm{MW}$ and $\mathrm{YW}$. Year of birth only significantly $(p<0.01)$ influenced at $3 \mathrm{MW}$ with a trend of 2007>2008>2006. Difference of year of birth at 3MW could not be justified by valid reason. However, it might be due to sampling fluctuation or environmental deviation between years. Year of birth did not differ significantly ( $p>0.05)$ between 6MGR and 12MGR.

Effect of season of birth: Table 5 shows that season of birth had no significant ( $p>0.05)$ effect on BW, $9 M W$ and YW but had significant effect on 3MW (p<0.001), 6MW $(p<0.01)$ and WW $(p<0.01)$. The trend of weight on seasons was summer>winter>rainy for 3MW and winter>summer $>$ rainy for $6 \mathrm{MW}$ and WW. Dhillon et al. (1971) reported that month of birth significantly contributed to the variation in BW. He stated that in general, calves born during February to April were heavier than those born during December to January. This variation is due to the availability of pastures to the pregnant dams. The 12MGR significantly $(p<0.05)$ differed among the seasons of birth, but did not differ significantly $(p>0.05)$ at 6 MGR

\section{Estimates of Variance components}

Estimates of variance components of traits studied obtained in single-trait analyses are shown in Table 6. The additive genetic variance for BW, 3MW, 6MW, WW, 9MW, YW, 6MGR and 12MGR were 2.387, $31.25,103.763,432.414,474.191,729.318,0.001$ and 0.002 , respectively, and non-additive variances for them were $2.42,35.53,114.88,492.60,586.43,797.66,0.001$, and 0.001 respectively. 
Table 6. Variance components of body weight and growth traits of Red Chittagong Cattle

\begin{tabular}{|l|c|c|}
\hline \multirow{2}{*}{ Trait } & \multicolumn{2}{|c|}{ Variance components } \\
\cline { 2 - 3 } & Additive genetic & Non-additive \\
\hline BWT & 2.39 & 2.42 \\
3MWT & 31.25 & 35.53 \\
GMWT & 103.76 & 114.88 \\
WWT & 432.41 & 492.60 \\
9MWT & 474.19 & 586.43 \\
12MWT & 729.32 & 797.66 \\
6MGR & 0.001 & 0.001 \\
12MGR & 0.002 & 0.001 \\
\hline
\end{tabular}

\section{Estimates of heritability}

Estimated heritability of BW, 3MW, 6MW, WW, 9MW, 12MW, 6MGR and 12MGR (Table 7) of the present study were $0.497 \pm 0.051,0.468 \pm 0.060, \quad 0.475 \pm 0.053, \quad 0.467 \pm 0.063, \quad 0.447 \pm 0.067, \quad 0.478 \pm 0.060$, $0.499 \pm 0.048$ and $0.653 \pm 0.213$ respectively. Estimated heritability of BW in the present study was slightly higher than the value obtained by Alam et al. (2007) found from Red Chittagong Cattle, Ahunu et al. (1997) found from pure and crossbred N'Dama and West African Shorthorn cattle and Padua and Silva (1996) found from graded Chianina $\times$ Nelore cattle who reported the same to be $0.45,0.45$ and 0.46 respectively. But this result agrees with the result observed by Shojo et al. (2005) on Japanese Black cattle ranged from 0.40 to 0.70 for growth traits.

Table 7. Phenotypic correlation (below the diagonal) and heritability (on the diagonal) among the body weight and growth traits of Red Chittagong Cattle

\begin{tabular}{|c|c|c|c|c|c|c|c|c|}
\hline & BWT & 3MWT & $6 \mathrm{MWT}$ & WWT & 9MWT & 12MWT & 6MGR & 12MGR \\
\hline BWT & 0.497 & & & & & & & \\
\hline 3MWT & 0.15 & 0.468 & & & & & & \\
\hline 6MWT & $0.22^{\star}$ & $0.81^{\star \star}$ & 0.475 & & & & & \\
\hline WWT & $0.54^{\star \star}$ & $0.67^{\star \star}$ & $0.74^{\star \star}$ & 0.467 & & & & \\
\hline 9MWT & 0.19 & $0.50^{\star \star}$ & $0.68^{\star \star}$ & $0.74^{\star \star}$ & 0.447 & & & \\
\hline 12MWT & 0.21 & $0.73^{\star \star}$ & $0.75^{\star \star}$ & $0.68^{\star \star}$ & $0.68^{\star \star}$ & 0.478 & & \\
\hline 6MGR & 0.06 & -0.01 & -0.02 & 0.27 & 0.04 & -0.16 & 0.499 & \\
\hline 12MGR & 0.09 & 0.24 & 0.05 & 0.33 & $0.36^{*}$ & $0.70^{\star \star}$ &.$-0.40^{\star}$ & 0.653 \\
\hline
\end{tabular}

* Correlation is significant at 0.05 level of probability.

** Correlation is significant at 0.01 level

Heritability $\left(h^{2}\right)$ value for BW of the present study was within the range of published values. High heritability values of BW suggest that selection on the basis of individual performance will be effective in achieving increased gain in BW. Again, high $h^{2}$ of BW with large standard errors may be due to small number of data or erratic nature of BW i.e. high difference between maximum and minimum range of BW observed within the RCC calves because of on-station environmental stress faced by their dams during feeds crisis period.

The magnitude of direct heritability estimates for the growth traits (Table 7) decreased from BW (0.497) to $3 \mathrm{MW}(0.468)$, after that it increased in $6 \mathrm{MW}(0.475)$ and similar fluctuation continued in the next traits also. Meyer (1992) also observed the magnitude of direct heritability estimates for the growth traits to be similarly decreased from birth to weaning.

The (co)variance components from multi-trait analyses are shown in Table 8. The heritability $\left(h^{2}\right)$ and genetic correlation for BW, 3MW, 6MW, WW obtained from the multi-trait analyses, are shown in Table 9.

\section{Estimates of genetic correlation}

From the multi-trait analyses (Table 9), genetic correlation $\left(r_{G}\right)$ between BW and WW was the highest (0.531) among the traits considered. Rios et al. (2007) reported negative direct-maternal genetic correlation of Mexican Charolais cattle as $-0.65,-0.72$, and -0.84 for BW, adjusted WW and post weaning gain, respectively. 
Table 8. Estimates of (co)variance components of growth traits of RCC (multi-trait analysis)

\begin{tabular}{|l|c|c|c|c|}
\hline Component & BWT & $3 \mathrm{MWT}$ & $6 \mathrm{MWT}$ & WWT \\
\hline Non-Additive & 2.405 & 1.853 & 3.589 & 10.348 \\
& & 24.181 & 21.993 & 43.326 \\
& & & 38.683 & 59.038 \\
& & & & 160.092 \\
\hline Additive genetic & 2.329 & 1.610 & 3.574 & 10.036 \\
& & 20.239 & 21.746 & 38.273 \\
& & & 38.668 & 58.722 \\
& & & & 153.614 \\
\hline
\end{tabular}

Table 9. Heritability $\left(h^{2}\right)$ and genetic correlation $\left(r_{G}\right)$ of the growth traits of RCC (multi-trait analysis)

\begin{tabular}{|l|c|c|c|c|}
\hline Traits & BWT & 3MWT & 6MWT & WWT \\
\hline BWT & 0.498 & 0.23 & 0.38 & 0.53 \\
3MWT & & 0.456 & 0.78 & 0.69 \\
6MWT & & & 0.500 & 0.76 \\
WWT & & & 0.490 \\
\hline
\end{tabular}

* Values on the diagonal indicate the heritability of the trait

* Values above the diagonal indicate the genetic correlation between traits

Factors to be considered when selecting for growth traits, is the relatively large negative genetic correlation between direct growth and maternal genetic effects. Other non-genetic factors are proposed to cause the negative correlation between maternal genetic effect and direct individual growth (Robinson, 1996b; Lee \& Pollak (1997) and Meyer, (1997). According to Neser et al. (1996), Robinson (1996b) and Lee \& Pollak (1997), ignoring the effect of sirexyear or sirexherd-year-season interaction in the model causes the negative correlations between direct and maternal effects to be more pronounced. Likewise, Meyer (1997), who applied the "Falconer-Willham" model and additionally included sirexherd-year interaction, found that genetic correlations between direct and maternal to be considerably less negative compared to the 'usual' animal model

Findings of the present study revealed the reasonable phenotypic mean, higher heritability, and genetic correlation estimation of growth traits of Red Chittagong Cattle. From the breeding point of view it may be concluded that Red Chittagong Cattle may show quick response in selection and breeding program for body weight improvement and to establish a local breed. When estimating genetic parameters for growth traits of Red Chittagong Cattle maternal effects would also have to be accounted for.

\section{References}

Ahunu, B.K., Arthur, P.F. and Kissiedu, H.W.A. 1997. Genetic and phenotypic parameters for birth and weaning weights of purebred and crossbred N'Dama and West African Shorthorn cattle. Livestock Production Science. 51:165-171.

Alam, M., Bhuiyan, A.K.F.H., Ali, A. and Mamun, A. 2007. Genetic analysis of birth weight and milk production of Red Chittagong Cattle of Bangladesh. Bang. J. Anim. Sci. 36 (1\&2): 24-32.

Anantakrishnan, C.P. and Lazarus, A.J. 1953. Observations on some Indian cattle for a study of birth weight of calves. Indian J. Dairy Sci. 6:23-26.

Bhuiyan, A.K.F.H., Shahjalal, M., Islam, M. N., Rahman, A.K.M.A., Kewon, J.F. and Van Vleck, L.D. 2005. Characterization, conservation and improvement of Red Chittagong Cattle of Bangladesh. BAU Res, Prog. 16: 33.

Bhuiyan, M.S.A., Bhuiyan, A.K.F.H., Yoon, D.H., Jeon, J.T., Park, C.S. and Lee, J.H. 2007. Mitochondrial DNA diversity and origin of Red Chittagong Cattle. Proc. of the 15 th Plant and Animal Genome Conference, 13-17 January, 2007, San Diego. California, USA. pp.126.

Cartwright, T.C. 1980. Prognosis of zebu cattle: Research and application. J. Anim. Sci. 50(6): 1221-1226.

Dhillon, J.S., Acharya, R.M., Tiwana, M.S. and Nagpal, M.L. 1971. Non-genetic factors affecting birth weight in Hariana cattle. Indian J. Dairy Sci. 24: 96-102.

Falconer, D.S. and MacKay, T.F.C. 1996. Introduction to quantitative genetics, $4^{\text {th }}$ Edition Longman. 
Ferreira, G.B., Macneil, M.D. and Van Vleck, L.D. 1999. Variance components and breeding values for growth traits from different statistical models. J. Anim. Sci., 77: 2641-2650.

Groeneveld, E. 1998. VCE 4.25 user's guide and reference manual version1.1. Institute of Animal Husbandry and Animal Behaviour. Mariensee, Federal Agricultural Research Centre, Germany.

Habib, M.A., Bhuiyan, A.K.F.H., Bhuiyan, M.S.A. and Khan, A.A. 2003. Performance of Red Chittagong Cattle in Bangladesh Agricultural University Dairy Farm. Bangladesh J. Anim. Sci. 32(1-2): 101-108.

Hasnath, M.A. 1974. Studies on crossbred cattle. Research Bulletin 1. Department of Animal Breeding and Genetics, Bangladesh Agricultural University, Mymensingh, pp. 1-24.

Hossain, M.M., Bhuiyan, M.S.A., Bhuiyan, A.K.F.H. and Hanotte, O. 2005. Red Chittagong-Indigenous Cattle Genetic Resource with promise in Bangladesh. Proceedings of the AHAT/BSAS International Conference, Published by British Society of Animal Science. 2: 82-83

Khan, M.K.I., Ali, A., Husain, S.S. and Bhuiyan, A.K.F.H. 1999. Reproductive performances of different genetic group of cows under farm condition. Bangladesh J. Anim. Sci. 27(1-2): 59-64.

Lee, C. and Pollak, E.J. 1997. Relationship between Sire x Year interaction and direct maternal genetic correlation for weaning weight of Simmental cattle. J. Anim. Sci, 75: 68-75.

Meyer, K. 1992. Variance components due to direct and maternal effects for growth. Livest. Prod. Sci. 57 : 385-395.

Meyer, K. 1997. Estimates of genetic parameters for weaning weight of beef cattle accounting for direct-maternal environmental covariances. Livest. Prod. Sci. 52: 187-199.

Neser, F.W.C., Konstantinov, K.V. and Erasmus, G.J. 1996. The inclusion of herd-year season $\mathrm{x}$ sire interaction in the estimation of genetic parameters in Bosmara cattle. S. Afr. J. Anim. Sci. 26: 75-78.

Padua, J.T. and Silva, R.G. 1996. Estimation of genetic parameters and factors involved in the performance of graded Chianina $\times$ Nelore cattle. Animal Breedng Abstracts, 64(5-8): 604.

Peters, S.O., Nwosu, I.C., Ozoje, M.O. and Ikeobi, C.O.N. 1998. Genetic parameter estimates for growth traits in cattle genotypes. Proc 6th Wrld Congr. Genetics Appl. Livest. Prod, 23: 101-104.

Rege, J.E.O. and Famula, T.R. 1993. Traits of Australian beef cattle. Livest. Prod. Sci. 31: 179-204.

Rios, U., Martinez, A., Velazquez, G., Tsuruta, S., Bertrand, J.K., Vega Murillo, V. E. and Montano Bermudez, M. 2007. Estimates of genetic parameters for growth traits of Mexican Charolais cattle. Tecnica Pecuaria en Mexico, 45(2): 121-130.

Robinson, D.L. 1996. Models which might explain negative correlation between direct and maternal genetic effects. Livest. Prod. Sci. 45: 111-122.

Shojo, M., Yong, J.A., Anada, K., Oyama, K. and Mukai, F. 2005. Estimation of genetic parameters for growth and feed utilization traits in Japanese Black cattle. Animal Science Journal, 76(2): 115-119

Singh, B.B. and Tyagi, J.C. 1970. Magnitude of effects of factors affecting birth weight of Hariana calves. Indian vet. J. 47:851-854.

Singh, S.B. and Desai, R.N. 1959. Inheritance of birth weight in Hariana cattle. Indian J. Dairy Sci.12:51-55

Statistical Analysis System (SAS). 2000. SAS/STAT User's Guide, $8^{\text {th }}$ edn. SAS Institute, Cary, NC.

Turner, J.W. 1980. Genetic and biological aspects of zebu adaptability. J. Anim. Sci, 50: 1201-1205.

Van der Westhuizen, J. and Matjuda, L.E. 1999. Breeding objectives. In: Beef breeding in South Africa (Ch. 5). Edcholtz., M.M., Bergh, L. and Bosman, D.J., Agric. Res. Council (Animal Improvement Institute), Irene, pp 27. 